\title{
PALEOAMBIENTES E CULTURAS DO PALEOLÍTICO SUPERIOR NO CENTRO E NORTE DE PORTUGAL: BALANÇO E PERSPETIVAS DE INVESTIGAÇÃO
}

\author{
THIERRY AUBRY ${ }^{(1)}$, LUCA ANTONIO DIMUCCIO ${ }^{(2)} \&$ HELENA MOURA $^{(3)}$
}

Resumo:

\begin{abstract}
Upper Palaeolithic cultures and palaeoenvironments in Central and Northern of Portugal: assessment and research prospects

The archaeological research developed during the last decade of the 20th-century in Central and Northeast Portugal established a palaeoenvironmental and chronostratigraphic framework for the Upper Palaeolithic occupation of these regions, and brought to light the operative schemes used for the production of stone tools from the locally available raw material resources. Between 40,000 and 12,000 cal BP, the preservation of the archaeological record was strongly conditioned by sedimentary processes related to rapid changes in global climate. In the Sicó Massif (Central Portugal), artefacts and ecofacts are mainly found in karst caves and rock-shelters (locally called "buracas") whose archaeostratigraphic sequences are discontinuous, affected by erosive events (hiatuses and stabilization), and variably preserved. The archaeological sites along the North bank of the Mondego River (Central Portugal) are associated with flint outcrops and their preservation in Pleistocene alluvium-colluvium sediments, with an aeolian component found in closed karst depressions of the Outil/Cantanhede Plateau. In the Côa Valley (Northeast of Portugal), the open-air sites are located on ancient rock-terrace surfaces related to Upper Pleistocene fluvial downcutting, as well as in topographic depressions of the planation surfaces of the "Meseta" granitoids. The procurement of flint and silcrete reveals a large social network, extending from the Estremadura to the Northern Meseta, which indicates that, in the wider context of the Iberian Peninsula, the current distribution of Upper Palaeolithic sites is not a genuine reflection of the density of this period's human occupation. Only the implementation of a systematic surveying approach for site detection based on geological-geomorphological models, such as those used in the Côa Valley and the Sicó Massif, will allow a more accurate reconstitution of that occupation.
\end{abstract}

Os trabalhos de arqueologia desenvolvidos desde o início da última década do século XX no Centro e Nordeste de Portugal permitem estabelecer um quadro paleoambiental e cronoestratigráfico das várias fases de ocupação durante o Paleolítico Superior, bem como aperceber caraterísticas da adaptação técnica da produção das indústrias de pedra lascada, em função dos recursos líticos disponíveis localmente. Todavia, entre 40,000 e 12,000 cal BP a preservação do registo arqueológico foi fortemente condicionada pelos processos sedimentares decorrentes de bruscas mudanças nas condições climáticas globais. No Maciço de Sicó (Centro de Portugal) foram detetados artefactos e ecofactos essencialmente em cavidades cársicas e abrigos sob rocha (localmente denominados "buracas"). As sequências arqueoestratigráficas são descontínuas e terão sofrido diversas fases erosivas, que se revelam por lacunas sedimentares e superfícies de estabilização, com distintos graus de preservação. Os sítios arqueológicos da margem Norte do Rio Mondego (Centro de Portugal) estão associados a afloramentos de sílex e a sua preservação em sedimentos alúviocoluviais do Plistocénico, com uma componente é́lica em depressões cársicas fechadas no Planalto de Outil/ Cantanhede. No Vale do Côa (Nordeste de Portugal), os sítios ao ar livre localizam-se em antigas superfícies de erosão relacionadas com o encaixe da rede hidrográfica durante o Plistocénico Superior, assim como em depressões topográficas abertas nas superfícies aplanadas dos granitóides no limite da "Meseta". O estudo do aprovisionamento em sílex e silcretos revela contactos de longa distância entre a Estremadura e a Meseta Norte, pelo que o mapa dos sítios do Paleolítico Superior atualmente disponível, no contexto mais geral da Península Ibérica, não constituirá uma imagem completa da densidade de ocupação humana deste território durante aquele período. Para obter uma representação mais rigorosa dessa ocupação necessitaremos inevitavelmente da aplicação sistemática de métodos de prospeção baseados em modelos de cariz geológico-geomorfológico, tal como já parcialmente estabelecido para o Vale do Côa e o Maciço de Sicó.

Palavras-chave: Paleolítico Superior, Portugal, Vale do Côa, Baixo Mondego.

Keywords: Upper Palaeolithic, Portugal, Côa Valley, Lower Mondego.

Received: 12 October, 2016; Accepted: 7 February, 2017

\section{VELHAS ROTAS E NOVOS CAMINHOS DA INVESTIGAÇÃO}

Apesar da rapidez da recuperação do atraso acumulado nos meios humanos e estruturais da investigação arqueológica, relativamente a outros países da Europa, registada nas três últimas déca- das do século XX, as carências humanas, financeiras e os constrangimentos inerentes aos trabalhos da arqueologia de emergência acentuaram-se na passagem para o século XXI. Por um lado, o número de escavações em sítios com níveis de ocupação do Paleolítico Superior diminuiu em Portugal e,

\footnotetext{
${ }^{(1)}$ Fundação Côa Parque, Rua do Museu, 5150-610 Vila Nova de Foz Côa, Portugal.

${ }^{(2)}$ CEGOT - Centro de Estudos em Geografia e Ordenamento do Território, Colégio de S. Jerónimo, Universidade de Coimbra, 3004-530 Coimbra, Portugal Autor correspondente: Dimuccio L.A. (E-mail: luca@ci.uc.pt).

${ }^{(3)}$ Direção Regional de Cultura do Centro, Rua Olímpio Nicolau Rui Fernandes, 3000-303 Coimbra, Portugal.
} 
por outro, apesar de uma relativa multiplicação dos trabalhos académicos sobre os materiais recolhidos e acumulados durante a última década do século $\mathrm{XX}$, ainda se aguardam as sínteses dos resultados obtidos no âmbito de projetos então iniciados (ZILHÃO 1996, 2001; AUBRY \& BICHO 2006; AUBRY 2013).

O quadro cronoestratigráfico da ocupação humana durante o Paleolítico Superior em Portugal, bem como as grandes linhas da evolução da flora e da fauna, foram sumariamente definidos por ROCHE (1964), tendo sido estabelecido um panorama mais pormenorizado ao longo dos anos 90 (MARKS et al. 1994; ZILHÃO 1996, 1997a, 2001; BICHO 1997). Os principais temas de estudo, como a datação, os processos culturais e antropológicos associados à transição do Paleolítico Médio para o Superior (ZILHÃO 2006), as transições do pré e pós Solutrense e a interpretação da variabilidade das indústrias líticas à escala do Sudoeste da Europa, foram já enunciados nas teses de doutoramento de ZILHÃO (1997a) e BICHO (2000).

Após a descoberta tardia de um património Paleolítico excecional no Vale do Côa (Nordeste de Portugal) têm-se vindo a acrescentar diversos dados como a cronologia das diferentes fases dos testemunhos gráficos conservados ao ar livre e a análise crítica do mapa de distribuição espacial dos sítios. A interpretação passou a integrar a possibilidade de um povoamento em áreas distintas do meio cársico, atestado nas sequências preservadas sob abrigos rochosos e no interior de grutas (ZILHÃO 1997b). Duas décadas mais tarde, os trabalhos de acompanhamento arqueológico de barragens permitiram a identificação de novos sítios nos contextos do Maciço Hespérico (i.e., fragmento mais contínuo e ocidental do Soco Varisco Europeu; RIBEIRO, 2013), no Vale do Rio Sabor (FIGUEIREDO et al. 2014; GASPAR et al. 2015, 2016), e no Baixo Vouga (PEREIRo 2015). Todavia, as prospeções arqueológicas realizadas ainda não revelaram nenhum sítio atribuível ao Paleolítico Superior numa larga banda de terrenos do litoral atual português, essencialmente constituída por sedimentos siliciclásticos do Cretácico Superior e do Cenozoico.

Neste breve balanço apresentamos os principais dados conhecidos até à data e uma reflexão sobre a contribuição dos sítios do Centro e Nordeste de Portugal (correspondente, grosso modo, às bacias hidrográficas do Baixo Mondego e do Rio Douro, respetivamente) para estes temas, bem como das perspetivas para uma nova fase de investigação (Fig. 1).

\section{O (DES)POVOAMENTO DO INTERIOR NORTE...?}

Na porção portuguesa da bacia hidrográfica do Rio Douro, apesar da descoberta das gravuras de Mazouco (Fig. 1), atribuídas estilisticamente ao Paleolítico Superior (JORGE et al. 1981), as sondagens efetuadas em 1981 e 1982 nas proximidades não revelaram quaisquer vestígios de uma eventual ocupação coeva. BAPTISTA (1983) contestou a possibilidade de existência destes indícios da presença humana durante este período. Como consequência da integração de uma metodologia estabelecida para os sítios de ar livre da região de Rio Maior (MARKS et al. 1994; ZILHÃO 1997a) e dos resultados de modelos geomorfológicos para a deteção de sítios, constata-se um crescimento regular do efetivo dos sítios identificados no interior Norte português, desde a descoberta do sítio da Cardina no Vale do Côa em 1995 (ZILHÃo et al. 1995) (Fig. 2).

Há relação direta entre os resultados obtidos e os investimentos em meios e prospeções sistemáticas realizadas no seguimento do reconhecimento da arte paleolítica do Vale do Côa (AUBRY 2009). Para esta região dispõe-se agora de um quadro cronoestratigráfico pormenorizado, com representação de várias fases do Paleolítico Superior, consentâneo com as grandes linhas do modelo definido para a Estremadura Portuguesa (AUBRY et al. 2008b). Tivemos já a oportunidade de fazer um balanço atualizado do contexto da arte do Côa, fundamentado nos resultados das prospeções, das escavações e dos estudos realizados em sítios com sequências estratigráficas que conservam vestígios de várias ocupações humanas (VALLADAS et al. 2001; AUBRY 2009), tendo então sido apresentada a totalidade das datas obtidas pelo radiocarbono (AUBRY 2009) e pelos métodos da luminescência (MERCIER et al. 2009).

Apesar de um contexto geológico (caraterizado por rochas de natureza ácida) desfavorável à conservação dos restos bióticos plistocénicos, a presença de intercalações calcossilicatadas nos filitos e metagrauvaques da Formação de Desejosa conduziu à preservação de restos de fauna num contexto datado do Dryas recente, até à data fenómeno unicamente circunscrito ao sítio do Fariseu (GABRIEL \& BÉAREZ 2009) e, com um grau menor de preservação, na Cardina (Fig. 2). Da análise sedimentológica e micromorfológica dos contextos de deposição coevos da ocupação paleolítica (SELlAMI 2009a, 2009b; BERGÁdA 2009; AUBRY et al. 2010b) resultou uma reconstituição da evolução paleoambiental e das modalidades de exploração dos recursos pelos grupos préhistóricos, apresentada ao público no Museu do Côa, inaugurado em Julho de 2010.

Os resultados do estudo das indústrias líticas indicam que a tecnologia utilizada para o talhe da pedra, apesar de fortemente condicionada pela ausência regional de sílex e adaptada à utilização predominante dos recursos autóctones (AUBRY et al. 2016a), apresenta diferenças nas modalidades técnicas de produção dos suportes das barbelas, em 


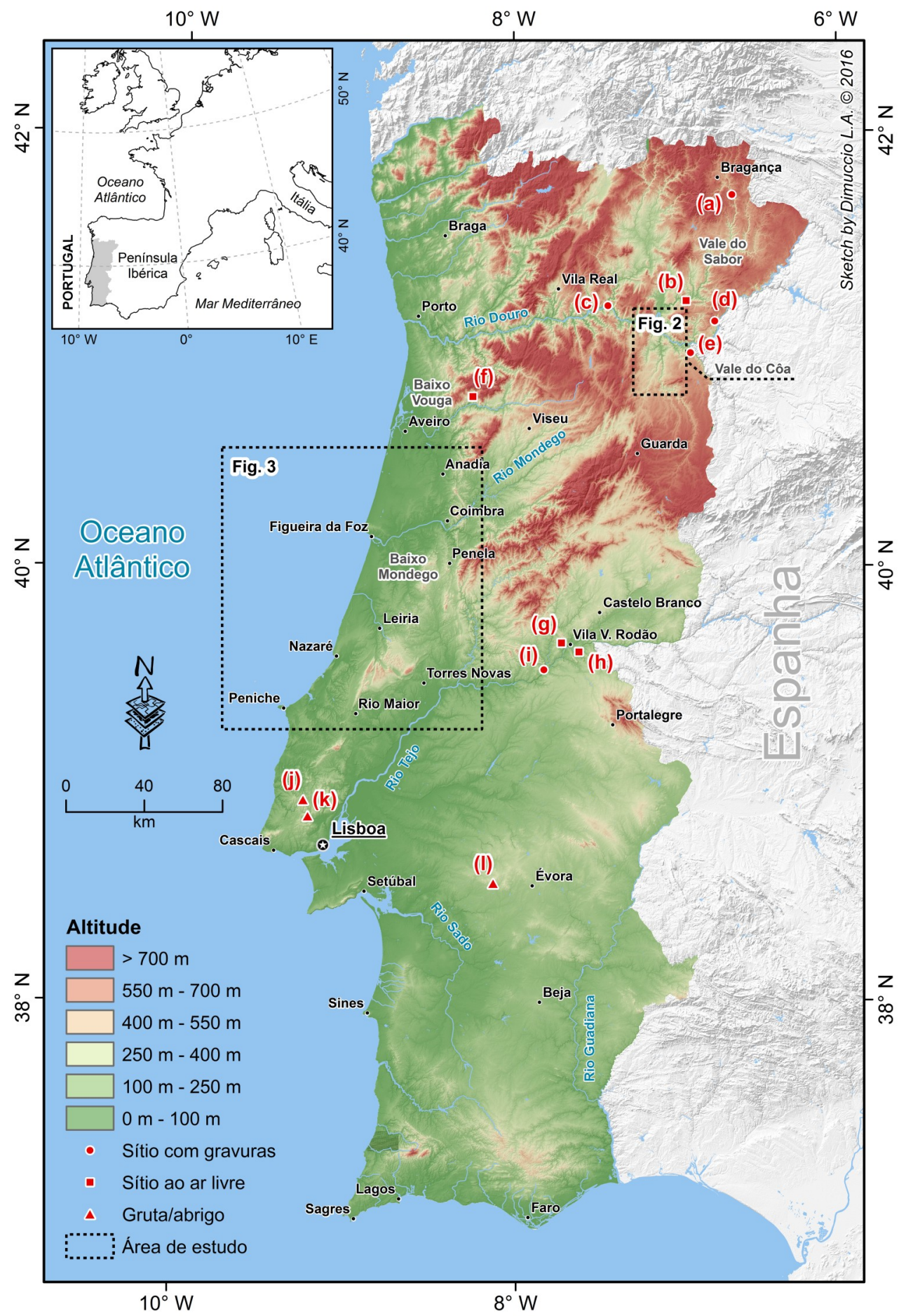

Fig. 1. Esboço hipsométrico e de localização das áreas analisadas no território português. O modelo digital de elevação foi elaborado com uma resolução geométrica de $25 \times 25$ m de pixel. Relevo em sombreado retirado de Global Imagery and Shaded Relief, Europe and Africa (Copyright (C 2001-2008 ESRI). Sítios arqueológicos do Paleolítico Superior conhecidos fora dos limites estabelecidos para as duas áreas de estudo consideradas neste trabalho (i.e., Centro e Nordeste de Portugal): (a) Gravuras do Alto Sabor, Pousadouro, Sampaio e Fraga Escrevida; (b) Sítio ao ar livre da Foz da Ribeira do Medal (Mogadouro); (c) Gravuras da Foz do Rio Tua; (d) Gravuras de Mazouco; (e) Gravuras do sítio de Redor do Porco; (f) Sítio ao ar livre do Vau; (g) Sítio ao ar livre de Vilas Ruivas; (h) Sítio ao ar livre de Castelejo; (i) Gravura do Baixo Ocreza; (j) Gruta de Salemas; (k) Gruta do Pego do Diabo; (l) Gruta do Escoural.

Fig. 1. Hypsometric sketch and location of the study areas in the Portuguese territory. The digital elevation model was built with a geometric resolution of 25x25 m of pixel. Shading relief from Global Imagery and Shaded Relief, Europe and Africa (Copyright (C) 2001-2008 ESRI). Upper Palaeolithic sites outside the two study areas considered in this work (i.e., Central and Northern Portugal): (a) Alto Sabor, Pousadouro, Sampaio and Fraga Escrevida open-air rock-art; (b) Foz da Ribeira do Medal (Mogadouro) open-air site; (c) Foz do Rio Tua open-air rock-art; (d) Mazouco open-air rock-art; (e) Redor do Porco open-air rock-art; (f) Vau open-air site; (g) Vilas Ruivas open-air site; (h) Castelejo open-air site; (i) Baixo Ocreza open-air rock-art; (j) Salemas cave; (k) Pego do Diabo cave; (1) Escoural cave. 


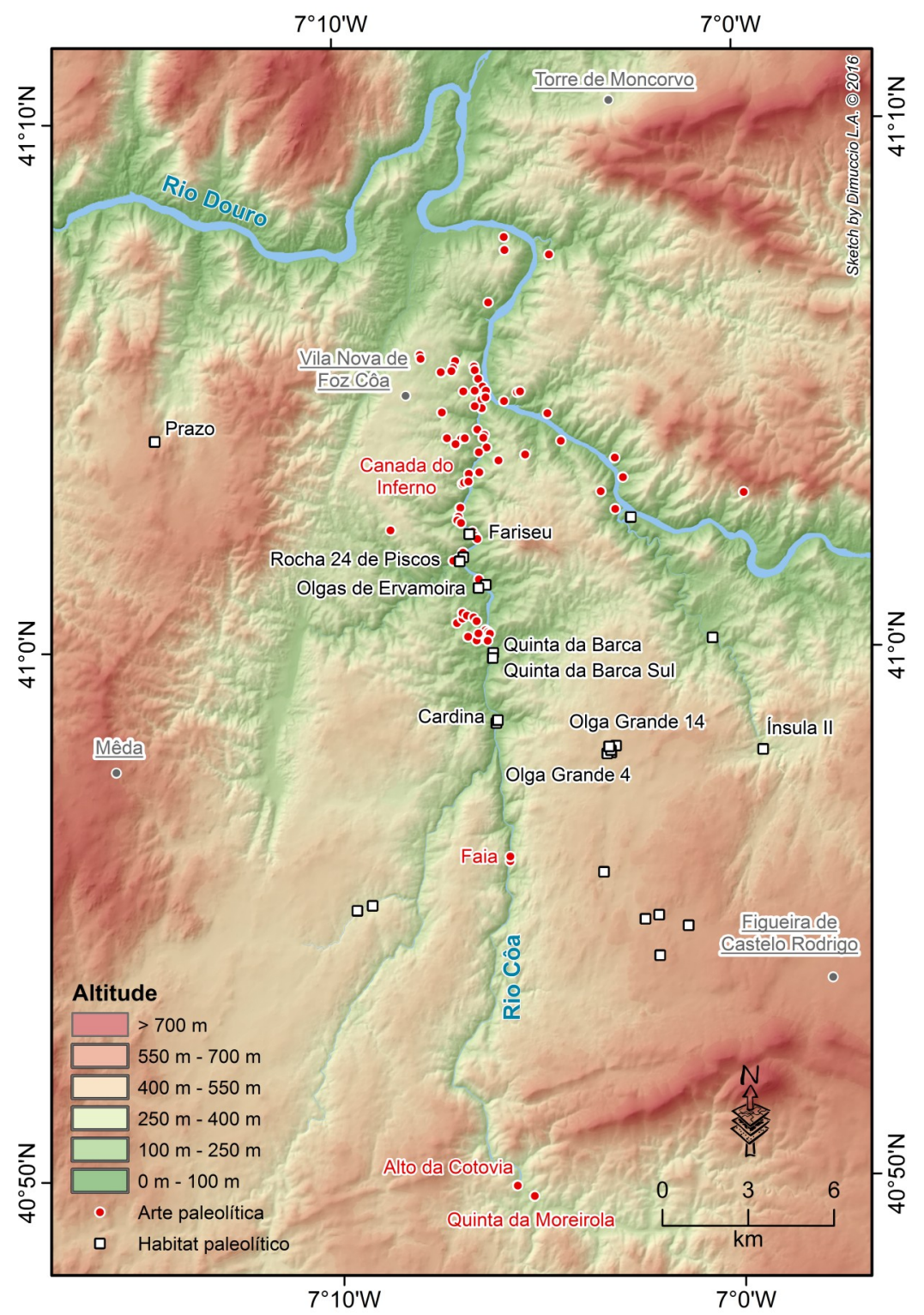

Fig. 2. Localização dos sítios de arte ao ar livre e de habitat do Vale do Côa.

Fig. 2. Location of the open-air rock-art and habitat sites of the Côa Valley.

relação aos dados conhecidos nas áreas próximas de fontes de sílex (KLARIC 2009). Todavia, apesar da variabilidade tipológica destes instrumentos compósitos de armas de caça, os utensílios diagnósticos são semelhantes aos destas regiões (AUBRY 2009; GAMEIRO 2012), bem como de outras do Sudoeste da Europa, durante o Gravettense recente (KLARIC et al. 2009). Já as pontas líticas solutrenses dos sítios do Côa apresentam mais semelhanças com as peças provenientes de sítios do Solutrense recente do Norte do que do Sul da Península (AUBRY 2009; AUBRY et al. 2015).

As descobertas de estruturas de combustão bem preservadas nos níveis de ocupação gravettenses dos sítios de Olga Grande 4 e 14 e de Cardina I (Fig. 2) conduziram a um estudo comparativo com um referencial de estruturas experimentais
(SAMPAIO 2009). Procurou-se ainda comparar a distribuição das outras categorias de vestígios espacialmente associados com o objetivo de propor interpretações funcionais (AUBRY 2009).

Um dos resultados mais interessantes sobre o contexto social dos artistas do Vale do Côa consubstanciou-se na elaboração de um referencial geológico de larga escala para o estudo do aprovisionamento em matérias-primas líticas das ferramentas de pedra lascada. A aplicação de métodos de caraterização demonstra a utilização e o abandono de peças em rochas siliciosas filonianas de grão fino de origens regionais (disponíveis a menos de $50 \mathrm{~km}$ de distância dos sítios) (AUBRY et al. 2016a), de outras, em muito menor quantidade, provenientes de fontes de matérias-primas da Estremadura Portuguesa (a cerca de 130-200 km) 
e, ainda, de silcretos do centro da Meseta Ibérica (a cerca de 160-250 km) (AUBRY et al. 2009, 2012b). A análise da distribuição geográfica dos afloramentos de sílex, silcretos e rochas siliciosas de grão fino utilizadas em níveis de ocupação do Vale do Côa revelou a presença sistemática e recorrente destes sílices alóctones. Peças estas que pela amplitude dos territórios explorados denunciam a existência de uma rede de contactos sociais e podem explicar a localização dos principais núcleos de arte ao ar livre no limite ocidental da Meseta e nos trajetos topográficos naturais entre os territórios desenhados pelas várias fontes representadas (AUBRY et al. 2012b). Tal estudo revelou a presença, em pequenas quantidades, mas sistematicamente e ao longo de milhares de anos, das mesmas variedades de sílex e outras rochas siliciosas de grão fino oriundas de formações geológicas da bacia hidrográfica do Rio Douro, na sua porção da Meseta, onde, até ao momento, nenhum sítio com ocupação segura do Paleolítico Superior foi identificado.

Apesar dos dados estabelecidos no Vale do Côa e das hipóteses elaboradas com base na presença de matérias-primas exóticas, grande parte do Maciço Hespérico continua a apresentar a densidade mais baixa de indícios da presença humana durante o Paleolítico Superior. Todavia, no novo caminho traçado pela descoberta da arte do Vale do Côa, o desenvolvimento de prospeções sistemáticas e a consideração dos processos erosivos e de conservação em modelos preditivos, juntamente com os trabalhos realizados para o acompanhamento e avaliação dos impactos de barragens, permitiram obter novos dados sobre as ocupações préhistóricas desta região. De facto, antes do acompanhamento arqueológico para a construção do empreendimento hidroelétrico do Baixo Sabor não se conheciam evidências claras de ocupação do Paleolítico Superior na margem direita do Rio Douro. De facto, poucos quilómetros a Norte do Vale do Côa, no Vale do Sabor, um dos mais importantes afluentes do Rio Douro, o sítio da Foz do Medal (Fig. 1) tem revelado uma importante sucessão arqueoestratigráfica com evidências de ocupação do Paleolítico Superior, na confluência entre a homónima linha de água (Ribeira do Medal) e o Rio Sabor, nos restos de um antigo terraço fluvial localizado $9 \mathrm{~m}$ acima do leito atual. Como resultado das escavações arqueológicas realizadas, evidencia-se a quase predominância na utilização de quartzo como matéria-prima durante quase todo o Paleolítico Superior, embora uma grande variedade de litologias exógenas pareça também ter sido utilizada (GASPAR et al. 2015).

No sítio da Foz do Medal, as matérias-primas líticas atestadas em níveis da ocupação gravettense correspondem essencialmente ao quartzo, nas suas diversas variedades, alcançando mais do $80 \%$ da totalidade do material recolhido (GASPAR et al.
2016). Esta predominância do quartzo, no entanto, parece diminuir nas ocupações do Solutrense, enquanto os quartzitos e silices se tornam as matérias-primas mais utilizadas. No mesmo sítio, GASPAR et al. (2015) apontam para uma utilização do quartzo que parece aumentar na fase Magdalenense, e a que corresponde um incremento na utilização de rochas siliciosas locais de grão fino.

Mais para Sudoeste, no Baixo Vouga (numa posição geomorfológica semelhante), com a descoberta do sítio de Vau (Fig. 1), evidenciou-se uma nova área com ocupação paleolítica a Norte do Rio Mondego (PEREIRO 2015; AUBRY et al. 2016b).

A descoberta de vestígios do Paleolítico Superior ao longo dos afluentes esquerdos e na margem direita do Rio Tejo (sítios ao ar livre de Castelejo e de Vilas Ruivas, respetivamente) (Fig. 1), na região de Vila Velha de Ródão (G.E.P.P. 1983; CUNHA et al. 2012; ALMEIDA et al. 2008), vem dar contexto regional a uma figura picotada de cavalo, gravada na margem do Baixo Ocreza (BAPTISTA 2001) (Fig. 1) e explicar a presença sistemática nos sítios do Magdalenense final do Côa de silcretos do Miocénico, provenientes de afloramentos localizados a Sul da Cordilheira Central, disponíveis em posição secundária nos terraços fluviais antigos do Rio Tejo (AUBRY et al. 2012b). Este facto revela que a implementação de prospeções sistemáticas nas regiões de Salamanca e de Valladolid (Espanha), locais de origens de matérias-primas também utilizadas no Vale do Côa, poderá, com grande probabilidade, vir a modificar o mapa atual da ocupação humana no interior da Península Ibérica durante o Paleolítico Superior.

O estudo geológico das sequências sedimentares dos sítios do Vale do Côa revelou uma taxa de sedimentação muito reduzida durante grande parte do Magdalenense. Tal situação não favorece uma boa discriminação dos vestígios pertencentes a esta cultura. A existência de mais fases de ocupações humanas durante o Tardiglaciar, para além das duas finais, reconhecidas com base na tipologia dos utensílios é, no entanto, sugerida por diferentes convenções morfológicas e estilísticas utilizadas nas gravuras incisas do Vale do Côa (BAPTISTA 2008, 2009; SANTOS 2012) e conhecidas em outras regiões da Península Ibérica com contextos datados do Magdalenense Médio e Superior, bem como pelas datas de cerca de 15,000-14,000 [datações através das técnicas de luminescência: thermoluminescence (TL) e optically stimulated luminescence (OSL)] das camadas 5 e 6 do Fariseu (MERCIER et al. 2006). Os raros vestígios líticos encontrados nestas unidades estratigráficas sofreram processos erosivos de natureza aluvial que não permitem conhecer com pormenor a tipologia dos utensílios líticos desta fase de ocupação.

No que respeita à correlação objetiva entre o faseamento da presença humana e a cronologia das 
gravuras ao ar livre das bacias hidrográficas do Rio Côa e do Rio Douro, a descoberta em 2007, na base da camada 8 (datada de 18,400 \pm 1600 anos, pelo método da luminescência) de um fragmento gravado que pertence ao painel 1 do Fariseu, vem fechar definitivamente o debate sobre a idade paleolítica da arte do Côa. A referida camada tapa a base de algumas das figuras mais antigas da sequência de sobreposição das 92 figuras picotadas do painel (AUBRY \& SAMPAIO 2009). Esta datação post quem, e a correlação com a sequência de sobreposição das figuras, demonstra que grande parte do painel 1 do Fariseu foi realizado em data anterior ao Magdalenense (AUBRY et al. 2013), sugerindo que, provavelmente, a totalidade destas sobreposições foi realizada durante uma mesma fase cultural. Tal atribuição da arte do Côa, em grande parte estilisticamente semelhante ao painel 1 do Fariseu, ao ciclo antigo da arte paleolítica, havia já sido sugerida, com base em critérios estilísticos, ainda antes da identificação das evidências materiais do Fariseu (BEHRMANN et al. 1996). Uma sondagem realizada durante a campanha de 2007 neste mesmo sítio revelou a existência de níveis de ocupação anteriores à camada 8 , onde foi exumado o fragmento de rocha gravada. $\mathrm{O}$ resultado de 22,581-23,174 cal BP (GrA-40167), obtido pelo método AMS, a partir de um carvão recolhido no topo da camada 9, confirma uma ocupação durante o Solutrense recente, já sugerida por uma lasca de afeiçoamento de peça foliácea, obtida por pressão que beneficiou de tratamento térmico com vista ao melhoramento da sua aptidão ao talhe. Porém, a utilização, na camada 10 , de variedades de matérias-primas líticas atestadas em níveis da ocupação Gravettense da região, sugere uma ocupação do sítio ainda durante esta fase.

A datação pré-Magdalenense das figuras sobrepostas da rocha 1 do Fariseu confere mais peso à relação técnica estabelecida pelo estudo traceológico dos picos afeiçoados em quartzito, descobertos num contexto Gravettense, no sítio de Olga Grande 4 (AUBRY 2009) (Fig. 2). No âmbito do projeto Labex Traceo 3D "Outils numériques pour l'analyse optique tridimensionnelle des surfaces" dirigido por H. PLISSON e iniciado em 2012, foi elaborado um novo referencial experimental para complementar os trabalhos preliminares (PLISSON 2009, 2015), objeto de documentação 3D e comparação com os impactos em motivos atribuíveis à fase antiga identificada na Canada do Inferno (Fig. 2).

Um outro elemento fundamental para a datação das várias fases do ciclo gráfico do Vale do Côa resulta também das três campanhas de escavação realizadas no Fariseu, que foram reveladoras de uma alta densidade de vestígios de arte móvel sobre placas e plaquetas de xisto (AUBRY 2009). Mais de 80 exemplares foram exumados e associados à ocupação do sítio durante o Dryas recente. Foi entretanto proposta a inclusão destas figuras zoomorfas de silhueta geométrica, gravadas por incisão múltipla (GARCÍA DIEZ \& AUBRY 2003; BAPTISTA 2009; AUBRY 2009; AUBRY \& SAMPAIO 2012) no estilo $V$, em paralelismo com um grupo de representações ao ar livre e em gruta do interior da Península Ibérica, atribuída à transição do Plistocénico para o Holocénico (BUENO RAMÍREZ et al. 2009). O contexto arqueológico destas representações vai constituir um referencial regional para as parietais, estilisticamente semelhantes, definindo um segundo grande momento da arte do vale. Os outros testemunhos gráficos encontrados na camada 3 do sítio de Quinta da Barca Sul (Fig. 2), datada pela termoluminescência do Dryas recente, na ocupação do Magdalenense final da camada 4 e do Gravettense final da base da camada 4 de Cardina I (Fig. 2), não são estilisticamente diagnósticos (AUBRY 2009).

Os estudos experimentais, desenvolvidos em torno da arte sobre suporte lítico rupestre e móvel em xisto, permitiram elaborar um leque de critérios morfotécnicos observáveis com a lupa e facilmente aplicáveis aos trabalhos de campo, com vista a diferenciar os estigmas deixados por emprego de utensílios líticos ou metálicos para a realização de incisões. Estes critérios levaram a tipificar as diferenças entre o recurso a utensílios de quartzo ou sílex/cristal de rocha. Em alguns casos, deteta-se uma boa correlação com a atribuição estilística à fase final (Dryas recente) e anteriores, pertencendo ao ciclo Magdalenense (AUBRY \& SAMPAIO 2012).

No âmbito deste estudo técnico, fundamentado num referencial experimental, foi incluído o único exemplar artístico móvel com pigmentos conservados. Trata-se de um seixo de quartzito $(148 \times 95 \times 37 \mathrm{~mm})$ recolhido em 2007 na unidade estratigráfica 4 do quadrado G79 do sítio do Fariseu, em associação estratigráfica com as placas de xisto gravadas com motivos figurativos ou geométricos. Os vestígios de pigmento mineral preenchem a parte central do seixo, em ambas as faces, com traços dispostos em bandas paralelas ao longo do eixo longitudinal e inscrevem-se na diversidade gráfica que carateriza os motivos geométricos, gravados ou pintados, sobre suportes móveis do Azilense, na categoria dos traços longitudinais simétricos. Com base nas experimentações realizadas, a peça encontrada na camada 4 do Fariseu resulta muito provavelmente de uma aplicação voluntária de pigmento seco num contexto simbólico, não parecendo resultar de atividades "domésticas" (AUBRY \& SAMPAIO 2012). A sua contemporaneidade com os contextos azilenses permite estender a distribuição geográfica desta forma de representação simbólica do final do Plistocénico Superior e revela a coexistência destas convenções gráficas puramente geométricas com as figurações zoomórficas, atestadas nas placas e plaquetas de xisto do mesmo horizonte cultural (AUBRY 2009). 
Durante o ano de 2012, no já referido sítio da Foz do Medal, na margem esquerda do Rio Sabor (Fig. 1), mais de um milhar de fragmentos de xisto gravados, alguns com motivos zoomórficos (maioritariamente cabras e cavalos associados, realizados por incisão simples ou múltipla), foram identificados durante os trabalhos de minimização de impacte das obras para a realização da barragem do Baixo Sabor (FigueIREDo et al. 2014). Estas representações integram-se na fase 2 do Vale do Côa (SANTOS 2012). A densidade dos vestígios de arte móvel sugere que a situação identificada no Fariseu não é exceção. As datações obtidas pelo método OSL indicam que os vestígios de arte móvel são anteriores ao Dryas III e à ocupação da Camada 4 do Fariseu.

A publicação dos levantamentos e das fotografias das gravuras dos diferentes sítios e fases artísticas paleolíticas do Vale do Côa prossegue com o seu ritmo próprio (BAPTISTA 2008, 2009). Várias hipóteses têm vindo a ser propostas para explicar a distribuição das rochas gravadas no espaço e a suas inter-relações (BAPTISTA et al. 2006, 2008; BAPTISTA \& SANTOS 2010). Paralelamente ao crescimento regular do efetivo de sítios de ocupação, as prospeções sistemáticas da equipa do Parque Arqueológico do Vale do Côa (BAPTISTA \& REIS, 2008; REIS 2012) têm vindo a identificar novas rochas ornamentadas, quase exclusivamente atribuíveis estilisticamente ao fim do Paleolítico Superior, tendo em conta o referencial arqueológico da arte móvel do Fariseu.

Nos outros afluentes do Rio Douro foram identificadas pequenas concentrações de arte rupestre no Vale do Sabor (BAPTISTA 2009) (Fig. 1), em zonas onde, a priori, as condições geomorfológicas não parecem muito favoráveis à conservação dos eventuais vestígios de ocupações humanas contemporâneas das atividades artísticas. Uma figura de auroque, picotada, que apresenta as mesmas convenções morfoestilísticas que as figuras da fase antiga do Côa, foi igualmente descoberta por M. REIS em 2011, alguns quilómetros a montante da confluência do Rio Águeda com o Douro, no sítio de Redor do Porco (BAPTISTA \& REIS 2011) (Fig. 1). Um antigo terraço fluvial, localizado a menos de $1 \mathrm{~km}$ da rocha gravada, possui elevado potencial de conservação dos eventuais níveis de ocupação coevos da gravura. Novos painéis com gravuras incisas, atribuíveis a uma fase recente do Paleolítico, foram detetados na Quinta da Moreirola e no Alto da Cotovia, localizada cerca de $12 \mathrm{~km}$ a montante da Faia (Fig. 2). A menos de algumas centenas de metros das gravuras, vestígios líticos foram recolhidos à superfície, num antigo terraço fluvial com preservação potencial de níveis arqueológicos (REIS 2012). Cerca de $50 \mathrm{~km}$ a jusante da foz do Rio Côa, várias figuras realizadas por picotagem (cervídeo, equídeo e bovino) foram detetadas em 2010 num abrigo na margem direita da foz do Rio Tua (TeIXeIRA et al. 2010) (Fig. 1). Os trabalhos nesta área, situada no limiar do leito de cheia atual, não evidenciaram a preservação de vestígios que pudessem constituir um contexto arqueológico para as gravuras.

Com base num levantamento geológico estrutural de terreno, na interpretação das imagens de satélite e numa avaliação do grau da colonização pelos líquenes nos painéis do Côa (gravados ou não gravados), foi proposto um modelo de conservação diferencial das superfícies rochosas, em função da sua orientação e ao longo do tempo. Fundamentado no potencial de conservação da superfície das diáclases, com direção tardi-hercínicas, algumas áreas foram escolhidas como teste e deste trabalho de campo resultou a descoberta de novos painéis gravados da Idade do Ferro e do fim do Paleolítico Superior (AUBRY et al. 2012a). Este modelo recentemente implementado vem complementar a metodologia de prospeção sistemática desenvolvida desde de 2005 por REIS (2012).

As sondagens realizadas em 2009 nas Olgas de Ervamoira (Fig. 2), com base na análise geomorfológica das fotografias aéreas (AUBRY et al. 2010a), demonstraram a preservação de vestígios líticos a cerca de três metros de profundidade, numa sequência sedimentar de mais de seis metros de espessura total. A topografia do substrato rochoso indica que, no limite da vertente e da planície aluvial, potenciais painéis com gravuras são suscetíveis de ter ficado soterrados por depósitos plistocénicos e holocénicos (AUBRY et al. 2010b; AUBRY 2011). Situação idêntica foi provada, aliás, pela escavação da rocha 1 do Fariseu, localizada na mesma margem do rio, a cerca de $2 \mathrm{~km}$ para jusante.

O modelo geomorfológico elaborado com base nos dados do Vale do Côa revela que situações semelhantes à do Fariseu podem existir em outras bacias dos afluentes do Rio Douro, o que parece poder confirmar-se pela identificação, em 2012, do sítio do Paleolítico Superior da Foz do Medal, acima referido.

\section{NA BACIA HIDROGRÁFICA DO BAIXO MONDEGO}

Apesar da fraca densidade de sítios arqueológicos cartografados, em ambas as margens do Baixo Mondego, destacam-se hoje duas concentrações. A primeira tem relação direta com a presença de sílex nos calcários do Jurássico Médio no Planalto de Outil/Cantanhede (Figs. 3 e 4). A utilização deste sílex está atestada nos sítios do Vale do Côa e no Baixo Vouga (AUBRY et al. 2016b). Raros indícios descobertos nos afloramentos indicam também a exploração de sílex do Jurássico Inferior da região de Anadia (ALMEIDA \& FREITAS 1995) (Fig. 3), atestado na ocupação Gravettense do sítio da Cardina I no Vale do Côa. A segunda está associada aos preenchimentos preservados nas grutas cársicas e abrigos sob rocha ("Buracas"; 
CunHa 1990) do Maciço de Sicó (Fig. 3). Estes últimos sítios foram detetados no âmbito do projeto de investigação de arqueologia espacial (Palaeoecologia do Baixo Mondego) no início dos anos 2000. Os poucos sítios da margem Norte do Rio Mondego aparecem em relação direta com a exploração dos nódulos de sílex do substrato, dis- poníveis em posição secundária nos depósitos detríticos de cobertura. O sítio da Gândara de Outil 1 foi objeto de uma escavação (AlmeIDA et al. 2006a, 2006c) que revelou a existência de numerosos restos de talhe correspondentes a uma produção de lamelas sobre lasca, num esquema operatório de tipo buril carenado. A comparação com o material

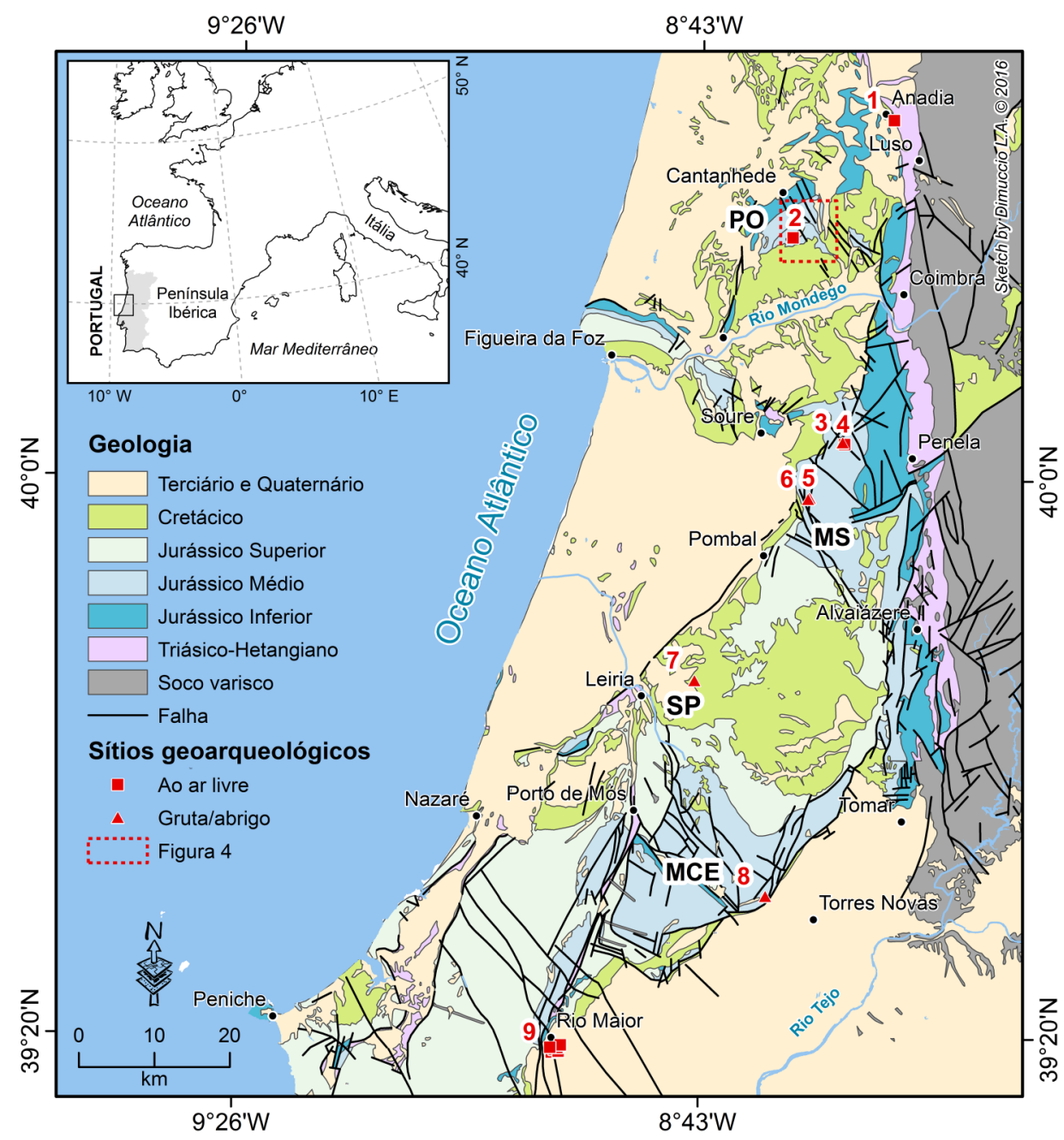

Fig. 3. Enquadramento geológico da região Centro de Portugal (onde se insere o Baixo Mondego) e localização dos sítios arqueológicos, com indícios de ocupação durante o Paleolítico Superior, no Planalto de Outil/ Cantanhede (PO), no Maciço de Sicó (MS), no Sinclinal de Pousos (SP) e no Maciço Calcário Estremenho (MCE). Base cartográfica de acordo com a Carta Geológica de Portugal, na escala 1:500 000, publicada em 1992 pelos Serviços Geológicos de Portugal (Oliveira et al. 1992). (1) Sítio ao ar livre de Monte dos Frades; (2) Sítio ao ar livre da Gândara de Outil 1 (ver Fig. 4); (3) Sítio ao ar livre do Vale das Buracas; (4) Abrigo do Vale dos Covões; (5) Buraca Grande; (6) Buraca Escura; (7) Abrigo do Lagar Velho; (8) Gruta da Oliveira; (9) Sítios ao ar livre da região de Rio Maior: Vale de Porcos, Vascas, Cabeço de Porto Marinho, Gato Preto, Casal de Felipe, Vale de Senhora da Luz, Terra do Manuel, Terra de José Perreira, Bairrada, Vale Comprido Barraca, Vale Comprido Cruzamento, Vale Comprido Encosta, Olival da Carneira e Carneira (ver ZILHÃO 1997a).

Fig. 3. Geological setting of the Central region of Portugal (which includes the Lower Mondego) and location of the Upper Palaeolithic sites in the Outil/Cantanhede Plateau (PO), in the Sicó Massif (SM), in the Pousos sinclinal (SP) and in the Estremadura Limestone Massif (MCE). Cartographic base-map according to the Geological Map of Portugal, at 1: 500 000, published in 1992 by the Geological Survey of Portugal (OLIVEIRA et al. 1992). (1) Monte dos Frades open-air site; (2) Gândara de Outil 1 open-air site (see Fig. 4); (3) Vale das Buracas open-air site; (4) Vale dos Covões rock-shelter; (5) Buraca Grande cave; (6) Buraca Escura cave; (7) Lagar Velho rock-shelter; (8) Oliveira cave; (9) Rio Maior open-air sites: Vale de Porcos, Vascas, Cabeço de Porto Marinho, Gato Preto, Casal de Felipe, Vale de Senhora da Luz, Terra do Manuel, Terra de José Perreira, Bairrada, Vale Comprido Barraca, Vale Comprido Cruzamento, Vale Comprido Encosta, Olival da Carneira and Carneira (see ZıLHão 1997a). 


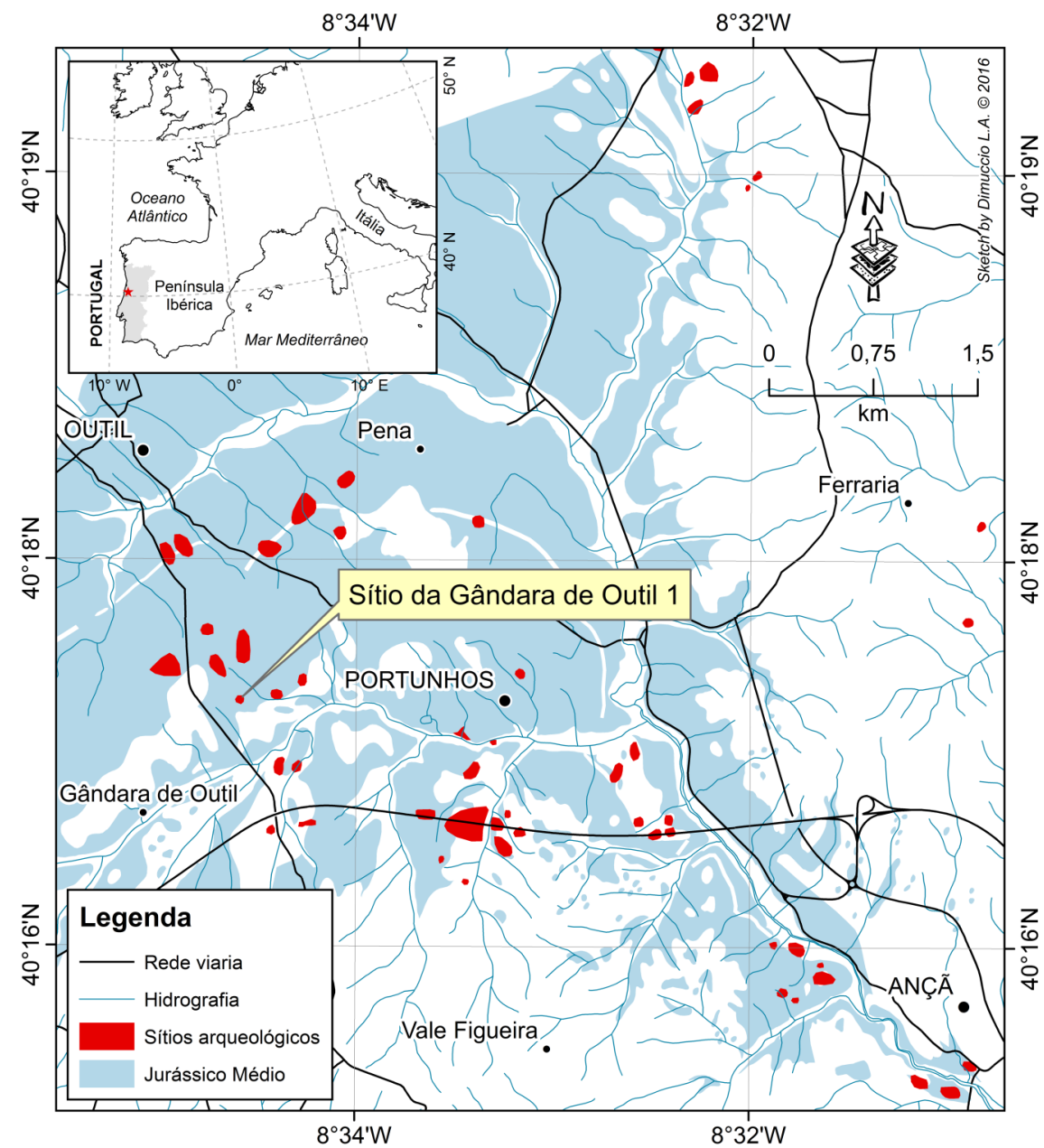

Fig. 4. Localização de pormenor dos sítios arqueológicos conhecidos no Planalto de Outil/ Cantanhede (in ALMEIDA et al. 2006a). A delimitação cartográfica das unidades carbonatadas do Jurássico Médio foi retirada da Carta Geológica de Portugal, na escala 1:50 000, folha 19-A (Cantanhede) (BARBOSA et al. 1988).

Fig. 4. Detailed location of known archaeological sites in the Outil/Cantanhede Plateau (in ALMEIDA et al. 2006a). Cartographic delimitation of the Middle Jurassic carbonate units according to the Geological Map of Portugal, at 1: 50 000, sheet 19-A (Cantanhede) (BARBOSA et al. 1988).

de Vale de Porcos, na região de Rio Maior (AUBRY et al. 2006) (Fig. 3), revelou grande semelhança entre os esquemas operatórios lamelar e laminar que, apesar de não eliminarem uma possível convergência com modos de produção atestados noutras regiões durante o Magdalenense inicial ou Médio, pesam a favor da hipótese de atribuição de um pequeno grupo de sítios portugueses de ar livre (Vale de Porcos e Gândara de Outil 1) e em gruta (Pego do Diabo, Escoural e Salemas) (Fig. 1) ao Aurignacense evoluído (ZILHÃO 1997a; ZILHÃO et al. 2010).

Embora a existência de vestígios arqueológicos nos depósitos preservados no carso do Maciço de Sicó seja conhecida desde os anos cinquenta (ALVES 1959), os sítios só foram objeto de trabalhos arqueológicos no início dos anos oitenta (RIBEIRO 1982) e no âmbito de dois projetos de investigação (Arqueologia Espacial na margem Sul do Baixo Mondego e Palaeoecologia do Baixo Mondego), na década de 1990 e na primeira metade de 2000

Os resultados do estudo das indústrias líticas (AUBRY \& MOURA 1994, 1995a, 1995b, 1996; AUBRY et al. 1994, 1997), a obtenção das datações radiométricas ${ }^{14} \mathrm{C}$ sobre ossos e carvões e o resultado dos estudos antracológicos e arqueozoológicos (AUBRY et al. 1997, 2001; FigUEIRAL \& TERRAL 2002) estabelecem um quadro da ocupação humana durante várias fases do Gravettense, do Solutrense e do Magdalenense, bem como das grandes linhas da evolução do contexto paleoambiental. A sequência cronoestratigráfica e os tipos de utensilagem em pedra lascada seguem o modelo proposto por ZILHÃO (1997a). O estudo do aprovisionamento em sílex indica relações regulares entre as ocupações nas cavidades cársicas (grutas) e abrigos do rebordo ocidental do Maciço de Sicó e as fontes de 
sílex da região de Leiria e do Vale do Nabão (AUBRY et al. 2012b, 2016b).

A análise sistemática dos restos faunísticos do Abrigo do Vale dos Covões encontra-se ainda em curso e os resultados do estudo dos restos antracológicos ainda não foram publicados. A análise tecno-tipológica dos vestígios, recolhidos neste sítio na sondagem de 2004 e nas escavações de 2005, foi integrada num estudo comparativo com indústrias de sítios do Centro e Nordeste de Portugal, para os níveis magdalenenses (GAMEIRO et al. 2008). Os vestígios do mesmo sítio, atribuíveis ao Gravettense recente com base na tipologia das barbelas constituídas essencialmente de microgravettes (KLARIC et al. 2009), foram analisados e comparados com séries líticas contemporâneas do Norte e Sul de França. Uma cronologia mais recente (Magdalenense final) é sugerida pelas datas obtidas pelo método ${ }^{14} \mathrm{C}$.

A abordagem traceológica foi aplicada à utensilagem retocada e aos suportes brutos de vários níveis desta mesma sequência, tendo os resultados sido comparados com os obtidos para as ocupações contemporâneas do Vale do Côa (AUBRY \& ARAÚJO IGREJA 2009).

$\mathrm{O}$ reexame e a abordagem geológica das sequências estratigráficas que preservam vestígios do Paleolítico Superior, conservados ao ar livre (Gândara de Outil 1 e Vale das Buracas), bem como em grutas (Buraca Grande e Buraca Escura) (Figs. 3 e 4), permitiram estabelecer o quadro das mudanças ambientais no Centro do país, entre 30,000 e 10,000 anos, assim como destacar a existência de várias fases erosivas e lacunas sedimentares (AUBRY et al. 2008a, 2011; ALMEIDA et al. 2006a, 2006b). A descontinuidade principal que existe em todas as sequências arqueoestratigráficas estudadas, datada de entre 29,500 e 32,000 cal BP, pode ser correlacionada com o evento frio Heinrich 3 (HEINRICH 1988; SÁNCHEZ GOÑI et al. 2000, 2008; entre outros). Esta descontinuidade, com caráter erosivo, deve correlacionar-se com a identificada no sítio do Lagar Velho (ZILHÃO \& TRINKAUS 2002) (Fig. 3), e poderá corresponder a uma mudança climática de amplitude regional/ suprarregional (a nível da Europa Ocidental), explicando-se assim, pela sua cronologia, a escassez dos vestígios da ocupação durante as fases iniciais do Paleolítico Superior (AUBRY et al. 2011).

\section{BALANÇO E PERSPETIVAS}

Os resultados obtidos nos sítios do Centro e o Nordeste de Portugal permitem hoje responder parcialmente às questões levantadas no fim da década de 1990. As datas obtidas sobre ossos associados com lamelas Dufour do sítio de Pego do Diabo (ZILHÃo et al. 2010) (Fig. 1), assim como as datas sobre osso obtidas na camada 8 do topo da sequência de ocupação do Paleolítico Médio da
Gruta Oliveira (Fig. 3), definem o intervalo cronológico (36,000-34,000 cal BP) durante o qual se produziu a passagem da tecnologia do Paleolítico Médio para as primeiras indústrias que integram componentes laminares e lamelares. As lamelas de tipo Dufour dos sítios atribuídos ao início do Paleolítico Superior em Portugal, quando comparadas com exemplares de outras regiões, podem ser atribuíveis a uma fase recente da cultura Aurignacense, cujas barbelas líticas com retoque alternado anunciam as peças diagnósticas do início do Gravettense (ZILHÃO et al. 2010).

Pelos dados disponíveis, a hipótese de existência de um desfasamento na chegada dos primeiros grupos humanos modernos entre o Norte e o Sul dos Pirenéus é a mais provável. Contudo, as reconstituições ambientais mostram que, ao longo da fachada Atlântica, os ciclos dos eventos frios de Heinrich aparecem associados às fases erosivas com um forte impacto na destruição do registo sedimentar e na conservação da organização espacial original dos vestígios, tanto ao ar livre como em gruta (AUBRY et al. 2010b, 2011). Contudo, o nosso conhecimento do impacto dos eventos frios de Heinrich sobre a fauna, a flora e no sistema hidrológico parece-nos ainda demasiado frágil, dado que é essencialmente baseado no registo proveniente de níveis de ocupação em grutas/abrigos, onde as sequências são geralmente truncadas e os vestígios resultam apenas de parte das atividades humanas, em relação direta com os recursos específicos das regiões cársicas. A este modelo deve ser acrescentado o facto de serem demasiado raros os níveis do fim do Paleolítico Médio datados com segurança, o que desautoriza a eliminação de um cenário alternativo, em mosaico, para o período compreendido entre 36,000 e 34,000 cal BP.

Devido a condições ambientais regionais, o registo arqueológico apresenta caraterísticas mais positivas para a preservação da organização espacial dos vestígios de ocupação tanto ao ar livre como em abrigo durante o Gravettense, por oposição ao resto do contexto europeu, mais profundamente afetado por processos crionivais (solifluxão, gelifração, etc.). Contudo, na atualidade, permanecem algumas lacunas de conhecimentos existentes no fim dos anos 1990. Insiste-se ainda na especificidade dos vestígios de ocupação do carso, preponderantes nas reconstituições paleoambientais e nas tentativas de interpretação das modalidades de exploração dos recursos pelos grupos paleolíticos. Grande parte do Maciço Hespérico do Centro e do Norte do país não revelou, até aqui, os indícios que atestariam a sua ocupação durante o Paleolítico Superior. Contudo, o aprovisionamento em matérias-primas líticas dá uma imagem bem distinta dos territórios efetivamente percorridos e explorados e da amplitude das redes sociais existentes (AUBRY et al. 2012b, 2016b). Antes de poder interpretar os mapas de distribuição de achados como uma ima- 
gem fiel dos territórios explorados e dos comportamentos das populações de caçadores-recolectores do passado, seria necessário reorientar os territórios de investigação e preparar os prospetores, nomeadamente no contexto de estudos de impacto, para detetar os vestígios líticos equivalentes aos materiais encontrados nos sítios do Vale do Côa, constituídos essencialmente por quartzo, quartzito, cristal de rocha e quantidades reduzidas de rochas siliciosas filonianas de grão fino e sílices alóctones.

A escolha da composição das equipas de prospeção e de acompanhamento no âmbito da minimização do impacto das numerosas barragens ainda previstas no território nacional, será fundamental para uma melhoria na aquisição dos dados para a próxima década. Devem ser dados os meios necessários para a deteção de sítios preservados em profundidade (por exemplo no limite das grandes bacias aluviais recobertas por aluviões holocénicos, ou nas áreas do litoral sob as dunas holocénicas) e devem as decisões políticas permitir financiar projetos de investigação suscetíveis de instaurar verdadeiras equipas pluridisciplinares estruturadas.

Finalmente, importa referir que é nosso entendimento que o estudo dos processos/ mecanismos sedimentares e de formação de cada sítio arqueológico deve ser entendido como o ponto de partida para a compreensão não somente das mudanças diacrónicas e de longo prazo da evolução humana, mas deve também constituir-se como o centro das controvérsias relativas à interpretação da cultura e do comportamento humano, especialmente quando se trata de situações onde a acumulação dos depósitos arqueológicos foi sobretudo controlada por processos naturais (como é o caso da Pré-história).

\section{AGRADECIMENTOS}

Trabalho desenvolvido no âmbito dos Projetos CAVE (PTDC/CTE-GIX/117608/2010) e PALÆCOA (PTDC/EPH -ARQ/0326/2014), cofinanciados pela Fundação para a Ciência e a Tecnologia, I.P. e pelo Fundo Europeu de Desenvolvimento Regional - FEDER, através do Programa Operacional Competitividade e Internacionalização (FCOMP-010124-FEDER-022634 e POCI-01-0145-FEDER-016605, respetivamente)

\section{BIBLIOGRAFIA}

AlmeidA, M.; Dimuccio, L.A.; Aubry, T.; NeVEs, M.J. \& CUNHA, L. 2006a. Enquadramento geomorfológico e crono-cultural do sítio arqueológico de Gândara do Outil 1. In: Actas do $2^{\circ}$ Congresso nacional de Geomorfologia, Coimbra, pp. 11-13

Almeida, M.; Neves, M.J.; Cunha, L.; Dimuccio, L.A. \& AUBRY, T. 2006b. Contributo da sequência cultural Pleistocénio-Holocénico para a compreensão da génese e evolução do canhão fluvió-cársico do Vale das Buracas. In: Actas do $2^{\circ}$ Congresso nacional de Geomorfologia, Coimbra, 11-13 Novembro 2004, pp. 69-75.
AlmeidA, M.; Aubry, T. \& Neves, M.J. 2006c. O sítio da Gândara do Outil: Um novo indício da presença Aurinhacense no Ocidente peninsular? In: Actas do IV $V^{o}$ Congresso de Arqueologia Peninsular, Faro, Setembro 14-19-09-2004, Promontório Monográfica 12: 419-431.

AlmeidA, N. \& FreitAs, D. 1995. Levantamento Arqueológico do Concelho de Anadia. Trabalho Policopiado, Instituto de Arqueologia, Fac. Letras da Universidade de Coimbra.

AlmeidA, N.; Deprez, S. \& De Dapper, M. 2008. The Palaeolithic occupation of the North-eastern of AlenTagus (Portugal): a geoarchaeological approach. In: Graphical Markers and Megalith Builders in the International Tagus, Iberian Peninsula, Primitiva Bueno-Ramirez, Rosa Barroso-Bermejo, Rodrigo de Balbín-Behrmann (Eds.), BAR International Series 1765, pp. 19-26.

Alves, R.V. 1959. Algumas grutas portuguesas de interesse arqueológico. Actas e Memórias do $1^{\circ}$ Congresso Nacional de Arqueologia, Vol. 1.

AuBry, T. 2009. 200 séculos da história do Vale do Côa: incursões na vida quotidiana do caçadores-artistas do Paleolítico. Trabalhos de Arqueologia 52, 512 p.

AUBRY, T. 2011. Géomorphologie des plaines alluviales du Côa: implications sur la visibilité et la conservation de l'art paléolithique de plein air. In: Actas da Reunião El Paleolítico Superior Peninsular - Noviedades des siglo XXI. Barcelona, pp. 239-254.

Aubry, T. 2013. Nord du Portugal. In: NOIRET, P. (Eds.), Le Paléolithique supérieur européen. Bilan quinquennal 2006-2011, Union Internationale des Sciences Préhistoriques et Protohistoriques, Commission VIII, ERAUL 130, Liège, pp. 137-144.

Aubry, T. \& AraúJo Igreja, M. 2009. Economy of lithic raw material during the Upper Paleolithic of the Côa Valley and the Sicó Massif (Portugal): technological and functional perspectives [Em linha]. In: Proceedings of the workshop Functional Studies of non flint stone tools: methodological improvements and archaeological inferences, M. de Araujo Igreja, I. Clemente (Org.), Lisbon 23-25 may 2008. Disponível: http://www.arte-coa.pt/Ficheiros/ Bibliografia/1203/1203.pt.pdf

AuBry, T. \& BichO, N.F. 2006. Le Paléolithique supérieur du Portugal (2001-2006). In: Le Paléolithique supérieur européen. Bilan quinquennal 2001-2006, Commission VIII. XV ${ }^{\circ}$ Congrès UISPP, Lisbonne (4-9 septembre 2006). Liège, ERAUL 115, pp. 135 145.

Aubry, T. \& Moura, M.H. 1994. Paleolítico da Serra de Sicó. Actas do $\mathrm{I}^{\circ}$ Congresso de Arqueologia Peninsular, Porto 12-18 Outubro 1993, In: Trabalhos da Sociedade Portuguesa de Antropologia e Etnologia 34: 3-60.

AuBry, T. \& MourA, M.H. 1995a. Nouvelles données sur les occupations paléolithiques de la Serra de Sicó. In: Actas da $3^{\circ}$ Reunião do Quaternário Ibérico, Coimbra, 27 Set.- $1^{\circ}$ Out. 1993, pp. 439-449.

AuBry, T. \& MoURA, M.H. 1995b. Les occupations humaines préhistoriques des cavités karstiques du massif calcaire de Sicó (Portugal). In: Livret-guide de l'excursion de la table ronde franco-portugaise sur le Karst au Portugal, Coimbra, 27-30/09/1995, pp. 27-31. 
Aubry, T. \& MourA, M.H. 1996. Novos dados sobre a rede cársica do Maciço do Ourão (Redinha, Pombal). Profundeza da Sicó 0, pp. 5-16.

AUBRY, T. \& SAMPAIO, J.D. 2008. Fariseu: new chronological evidence for open-air Palaeolithic art in the Côa valley (Portugal) [Em linha]. Antiquity, 82, 316, June 2008, disponível: http:// www.antiquity.ac.uk/projgall/aubry316 [Citado em 26/04/2011].

Aubry, T. \& SAMPAIO, J.D. 2009. Chronologie et contexte archéologique des gravures paléolithiques de plein air de la vallée du Côa (Portugal). In: RODRIGO DE Balbín Behrmann (Ed.) Actas do Coloquio "Arte Rupestre al Aire Libre en el Sur de Europa, Salamanca 15/17-06-2006, pp. 211-223.

Aubry, T. \& SAMPAIO, J.D. 2012. Novos dados para a abordagem técnica da arte rupestre e móvel do Vale do Côa. In: SANCHES, J. (Ed.), 1 ${ }^{\text {a }}$ MesaRedonda, Artes rupestres da Pré-História e da Pré -história: paradigmas e metodologias de registo. Lisboa, D.G.P.C. Trabalhos de Arqueologia 54, pp. 185-206.

AuBry, T.; MourA, H. \& ZILHÃO, J. 1994. Dados preliminares sobre a organização estratigráfica da Buraca Grande do Vale do Poio Novo (Redinha). Memórias e Notícias, Publicações do Museu de Mineralogia e Geologia da Universidade de Coimbra, 1992, pp. 119-132.

Aubry, T.; Fontugne, M. \& MourA, M.H. 1997. Les occupations de la Grotte de Buraca Grande depuis le Paléolithique Supérieur et les apports de la séquence holocène à l'étude de la transition Mésolithique/Néolithique au Portugal. Bulletin de la Société Préhistorique Française 94 (2), pp. 182-190.

Aubry, T.; Brugal, J.P.; ChauviÉRe, F.X.; Figueiral, I.; Moura, M.H. \& Plisson, H., 2001. Modalités d'occupation au Paléolithique supérieur dans la grotte de Buraca Escura (Redinha, Pombal, Portugal). Revista Portuguesa de Arqueologia 4 (2): 19-46.

Aubry, T.; AlmeidA, M.; NeVEs, M.J. 2006. The Middle-to -Upper Paleolithic transition in Portugal: An Aurignacian Phase or Not? In: BAR-YOSEF O.; ZILHÃo J. (Eds.). Towards a Definition of the Aurignacian. Lisbon: American School of Prehistoric Research/Instituto Português de Arqueologia, pp. 95-108

Aubry, T.; Almeida, M.; Dimuccio, L.; Gameiro, C.; NeVES, M.J. \& KLARIC, L. 2008a. Caractérisation et discontinuités des registres pédo-sédimentaires de l'occident péninsulaire entre 30.000 et 10.000 BP. In: Aubry, T.; Almeida, F.; AraúJo, A.C.; TIfFagom, M. (Eds.), Proceedings of the XV World Congress UISPP (Lisbon, 4-9 September 2006), Sessions C64 and C65, Space and Time: Which Diachronies, which Synchronies, which Scales? / Typology vs Technology, Vol. 21, 65, BAR S1831, pp. 9-21.

Aubry, T.; Zilhão, J. \& AlmeidA, F. 2008b. A propos de la variabilité technique et culturelle de l'entité gravettienne au Portugal : bilan des dernières découvertes et perspectives de recherche. In: Actes de la Table Ronde «Entités régionales d'une paléoculture européenne: Le Gravettien», 04/2004. Paleo 19, pp. 51-70.

Aubry, T.; Mangado Llach, X. \& SAmpaio, J. 2009. Estudo do aprovisionamento em matérias-primas.
In: AUBRY, T. (Ed.), 200 séculos da história do Vale do Côa: incursões na vida quotidiana do caçadores-artistas do Paleolítico. Trabalhos de Arqueologia 52, pp. 131-169.

Aubry, T.; Dimuccio, L.A.; Sampaio, J. \& Santos, A. 2010a. Olgas de Ervamoira: seis metros de arquivo da Pré-História nas margens do rio Côa. Coavisão 12, pp. 133-143.

Aubry, T.; Dimuccio, L.A.; BergÁDA, M.; SAMPAiO, J.D \& Sellami, F. 2010b. Palaeolithic engravings and sedimentary environments in the Côa River Valley (Portugal): Implications for the detection, interpretation and dating of open-air rock art. Journal of Archaeological Science 37: 3306-3319.

Aubry, T.; Dimuccio, L.A.; Almeida, M.; Neves, M.J.; ANGELUCCI, D. \& CUNHA, L. 2011. Palaeoenvironmental forcing during the Middle-Upper Palaeolithic transition in Central-western Portugal. Quaternary Research 75: 66-79

Aubry, T.; SAmpaio, J. \& Luís, L. 2011. Approche expérimentale appliquée à l'étude des vestiges du Paléolithique Supérieur de la Vallée du Côa (Portugal). In: Morgado, A. Baena Preysler, J.; GARCÍA GonzÁlez, D. (Eds.), La Investigación Experimental Aplicada a La Arqueología. Vol. 1: Tecnología y Traceología Lítica Prehistórica y $\mathrm{Su}$ Experimentación, Universidad de Granada, Granada, pp. 87-96.

AuBry, T.; Luís, L. \& DimuCCIO, L.A. 2012a. Nature vs. Culture: present-day spatial distribution and preservation of open-air rock art in the Côa and Douro River Valleys (Portugal). Journal of Archaeological Sciences 39: 848-866.

Aubry, T.; Luís, L.; Mangado Llach, J. \& Matias, H 2012b. We will be known by the tracks we leave behind: exotic lithic raw materials, mobility and social networking among the Côa Valley foragers (Portugal). Journal of Anthropological Archaeology 3: $528-550$

Aubry, T.; SANTOS, A. \& Luís. L. 2013. Stratigraphies du panneau 1 de Fariseu : analyse structurelle d'un système graphique paléolithique à l'air libre de la vallée du Côa (Portugal). In: P. PAILlET (dir.), Les arts de la Préhistoire : micro-analyses, mises en contextes et conservation. Actes du colloque «Micro-analyses et datations de l'art préhistorique dans son contexte archéologique», MADAPCA Paris, 16-18 novembre 2011, PALEO, numéro spécial, pp. 259-270.

Aubry, T., Luís, L., Mangado Llach, J. \& Matias, H. 2015. Adaptation to Resources and Environments during the Last Glacial Maximum by HunterGatherer Societies in Atlantic Europe. Journal of Anthropological Research 71 (4): 521-544.

Aubry, T.; BArbosA, A.F.; Luís, L.; SANTOS, A.T. \& Silvestre, M. 2016a. Quartz use in the absence of flint: Middle and Upper Palaeolithic raw materia economy in the Côa Valley (North-Eastern Portugal). Quaternary International. http:// dx.doi.org/10.1016/j.quaint.2015.11.067

Aubry, T.; Gameiro,C.; Mangado Llach,J.; Luís, L.; Matias,H. \& Pereiro, T.D. 2016b. Upper Palaeolithic lithic raw material sourcing in Central and Northern Portugal as an aid to reconstructing hunter -gatherer societies. Journal of Lithic Studies 3 (2) http://dx.doi.org/10.2218/jls.v3i2 
BAPTISTA, A.M. 1983. O complexo de gravuras rupestres do Vale da Casa (Vila Nova de Foz Côa). Arqueologia 8, pp. 57-69.

BAPtistA, A.M. 2001. Ocreza (Envendos, Mação, Portugal central): um novo sítio de arte paleolítica ao ar livre. In: Cruz, A.R.;OOSTERBEeK, L. (Eds.), Territórios, Mobilidade e Povoamento No Alto Ribatejo. II: Santa Cita e o Quaternário da Região. Perspectivas em diálogo (Arkeos; 11), CEIPHAR - Centro Europeu de Investigação da Pré-História do Alto Ribatejo, Tomar, pp. 163-192.

BAPTistA, A.M. 2008. Aspecto da Arte Magdalenense e Tardiglaciar no Vale do Côa. In: SANTOS, A.T., Luís, L. (Eds.) Do Paleolitico à Contemporaneidade. Actas do Fórum Valorização e Promoção do Património Regional 3, pp. 16-31.

BAPTISTA, A.M. 2009. O paradigma perdido: O Vale do Côa e a arte paleolitica de ar livre em Portugal. Porto, Edições Afrontamento; Parque Arqueológico do Vale do Côa

BAPTistA, A.M. \& REIS, M. 2008. Prospecção da arte rupestre no Vale do Côa e Alto Douro português: ponto da situação em julho de 2006. In: BALBÍN BEHRMANN, R. de (Ed.), Arte al aire libre en el Sur de Europa.Junta de Castilla y Léon, pp. 145-192.

BAPTISTA, A.M \& REIS, M. 2011. A rocha gravada de Redor do Porco: Um novo sítio de arte Paleolítica de ar livre no rio Águeda (Escalhão, Figueira de Castelo Rodrigo). Coavisão, 13, pp. 15-20.

Baptista, A.M. \& SANTOS, A.T. 2010. Confronting two sceneries on the same stage: from Gravettian-Solutrean to Magdalenian in Penascosa/Quinta da Barca (Vila Nova de Foz Côa, Portugal. In: BeTtencourt, A.M.S. SANCHES; M.J. AlVES, L.B. FÁBREGAS VALCARCE, R. (Eds), Conceptualising Space and Place on the role of agency, memory and identity in the construction of space from the Upper Palaeolithic to the Iron Age in Europe. Oxford, Archaeopress (BAR International Series 2058), pp. 61-69.

BAPtista, A.M.; SAnTos \& A.T.; CorreiA, D. 2006. Da ambiguidade das margens na Grande Arte de ar livre no Vale do Côa: Reflexões em torno da organização espacial do santuário Gravetto-Solutrense na estação da Penascosa/Quinta da Barca. Côavisão 8 , pp. 156-184

Baptista, A.M.; SAnTos, A.T. \& Correia, D. 2008. O santuário arcaico do Vale do Côa: novas pistas para a compreensão da estruturação do Bestiário Gravettense e/ou gravetto-solutrense. In: BALBÍN BEHRMANN, R. de (Ed.). Arte al aire libre en el Sur de Europa. Junta de Castilla y Léon, pp. 89-144.

Barbosa, B.; SoAres, A.F.; Rocha, R.B.; Manupella, G. \& Henriques, M.H. 1988. Carta Geológica de Portugal, escala 1:50 000, Folha 19-A (Cantanhede). Serviços Geológicos de Portugal, Lisboa.

BehrmanN, B.R.; Alcolea GonzÁlez, J.J. \& SAntoja GóMEZ, M. 1996. Arte rupestre paleolitico al aire libre de la cuenca del Duero: Siega Verde y Foz Côa. Fundación Rei Afonso Henriques, Zamora.

BergÁDA, M.M. 2009. Análisis micromorfológico de la secuencia sedimentaria de Cardina I (Salto do Boi, Vila Nova de Foz Côa, Portugal). In: AuBry, T (Ed), 200 séculos da história do Vale do Côa: incursões na vida quotidiana do caçadores-artistas do
Paleolítico. Trabalhos de Arqueologia, 52, pp. 112 127

BICHO, N.F 1997. Spatial, technological, and economic organization after the Last Glacial máximum in Portuguese Prehistory. In: FullolA, J.M.; SOLER, N. (Eds.), El món mediterranides prés del Pleniglacial (18.000-12.000), Séries Monográficas, 17, Museu d'Arqueologia de Catalunya, Girona, pp. 213.223.

BICHO, N.F. 2000. Technological Change during the Pleistocene-Holocene Boundary in Rio Maior, Portugal. Tomar: CEIPHAR.

Bueno Ramírez, P.; Balbín Behrmann, R. \& Alcolea GONZÁLEZ, J.J. 2009. Estilo V en el ámbito de Duero: Cazadores finiglaciaires en Siega Verde (Salamanca). In: BALBÍN BEHRMANN, R. de (Ed.), Arte Prehistórico al aire libre en el Sur de Europa. [S.l.], Junta de Castilla y Léon, pp. 259-286.

CunHA, L. 1990. As Serras Calcárias de Condeixa, Sicó, Alvaiázere - Estudo de Geomorfologia. Geografia Física I, Instituto Nacional de Investigação Cientifica, Imprensa Nacional, Casa da Moeda, 329 p.

Cunha, P.P.; Almeida, N.A.C.; Aubry, T.; Martins, A.A.; Murray, A.S.; Buylaert, J.P.; SOHBATI, R.; RAPOSO, L. \& RochA, L. 2012. Pleistocene sedimentary and human occupation records in the Arneiro depression (Lower Tejo River, central eastern Portugal). Geomorphology: 78-90.

FÁBreGA, R.V.; LOMBERA, A.H. 2011. A DESCOBERTA DA PRESENZA HUMANA NO NOROESTE. IN: CAINZOS, D.D, ACUÑA, M.V. (Eds), A prehistoriaen Lugo a luz das descobertas recentes. Actas do curso, Lugo, 24 e 25 de Abril 2009, pp. 63-82.

Figueiral, I. \& Terral, J.-F., 2002. Late Quaternary refugia of Mediterranean taxa in the Portuguese Estremadura: charcoal based paleovegetation and climatic reconstruction. Quaternary Science Reviews 21: 549-558

Figueiredo, S. C. S. DE; Nobre, L.; GASPAR, R.; CARron DO, J.; Cristo Ropero, A.; Ferreira, J.; Silva, M. J. DA \& MolinA, F. J. 2014. Foz do Medal terrace - an open-air settlement with paleolithic portable art, International Newsletter on Rock Art 68 , pp. $12-19$.

GABRIEL, S. \& BÉAREZ, P. 2009. Caçadores-pescadores do Vale do Côa: os restos de fauna do sítio do Fariseu. In: AUBRY, T. (Ed.), 200 séculos da história do Vale do Côa: incursões na vida quotidiana do caçadores-artistas do Paleolítico. Trabalhos de Arqueologia 52, pp. 331-339.

GAMEIRO, C. 2012. La variabilité régionale des industries lithiques de la fin du Paléolithique supérieur au Portugal. Tese de doutoramento, Univ. Paris I, Panthéon-Sorbonne, UFR d'Histoire de l'Art et d'Archéologie, Préhistoire-EthnologieAnthropologie.

GAmeiro, C.; Aubry, T. \& AlmeidA, F. 2008. L'exploitation des matières premières lithiques au Magdalénien final en Estrémadure portugaise : données sur les sites de Lapa dos Coelhos et de l'Abri 1 de Vale dos Covões. In: Aubry, T.; Almeida, F.; AraúJo, A.C. \& Tiffagom, M. (Eds.), Proceedings of the XV World Congress UISPP (Lisbon, 4-9 September 2006), Sessions C64 and C65, Space and Time: Which Diachronies, which Synchronies, which 
Scales? / Typology vs Technology, Vol. 21, 65, BAR S1831, pp. 57-67.

García Diez, M. \& Aubry, T. 2003. Grafismo mueble en el Valle de Côa (Vila Nova de Foz Côa, Portugal): la estación arqueológica de Fariseu. Zephyrus 55: 157-182.

Gaspar, R., Ferreira, J., Molina Hernandez, F., GarCÍA-Vadillo, F.J., Rebelo, P., Neto, N., 2015. Away from the edges: a new solutrean site in interior Iberia. Foz do Medal left bank, Sabor Valley, northeast Portugal (NW Iberia). Journal of Anthropological Research 71 (4), 545e 564.

Gaspar, R.; Ferreira, J.; CARrondo, J.; Silva, M.J. \& GARCÍA-VADILlO, F.X. 2016. Open-air Gravettian Lithic assemblages from Northeast Portugal: the Foz do Medal site (Sabor valley) Quaternary International 406: 44-64.

G.E.P.P. 1983. A estação paleolítica de Vilas Ruivas (Rodão), Campanha de 1979. Grupo para o Estudo do Paleolítico Português (com a colaboração de: SILVA, A.; Pimenta, C.M.; Lemos SANDE, F.; Zilhão, J.; Mateus, J; Raposo, L. \& Coutinho, M.J.), $O$ Arqueólogo Português, Série IV, 1, pp. 15-38.

HEINRICH, H. 1988. Origin and consequences of cyclic ice rafting in the northeast Atlantic ocean during the past 130,000 years. Quaternary Research 29, pp. 142-152.

Jorge, S.O.; Jorge, V.O.; Almeida, C.A.F.; SANCHES, M.J. \& SoEIRO, M.T. 1981. Gravuras rupestres de Mazouco (Freixo de Espada à Cinta), Arqueologia $3: 3-12$.

KLARIC, L. 2009. Les systèmes de production de supports d'armatures et leur place dans la gestion de ressources lithiques: une voie privilégiée pour la compréhension des sociétés gravettiennes de la Vallée du Côa. In: AUBRY, T. (Ed.), 200 séculos de história do Vale do Côa: Incursões na vida quotidiana dos caçadores-artistas do Paleolítico. IGESPAR, I.P. Trabalhos de Arqueologia 52, Lisboa, pp. 247-256.

Klaric L., Guillermin P. \& Aubry T. 2009. Des armatures variées et des modes de productions variables. Réflexions à partir de quelques exemples issus du Gravettien d'Europe occidentale (France, Portugal, Allemagne). Gallia Préhistoire 51, pp. 113-154.

Marks, A.; Bicho, N.; ZILHão, J. \& FerRing, C.R. 1994. Upper Pleistocene Prehistory in Portuguese Estremadura. Result of preliminary research. Journal of Field Archaeology 21: 53-68.

Mercier, N.; Valladas, H.; Aubry, T.; Zilhão, J.; Jorons, J.L.; Reyss, J.L. \& Sellami, F. 2006. Fariseu: first confirmed open-air palaeolithic parietal art site in the Côa Valley (Portugal) [Em linha]. Antiquity 80 (310). http://antiquity.ac.uk/ProjGall/ mercier/index.htm.

Mercier, N.; Valladas, H.; Froget H.; JoRons, J.L.; Reyss \& AUBRY, T. 2009. Application des méthodes de la luminescence à la datation d'occupations paléolithiques de la Vallée du Côa. In: AUBRY, T. (Ed.), 200 séculos da história do Vale do Côa: incursões na vida quotidiana do caçadores-artistas do Paleolítico. Trabalhos de Arqueologia 52, pp. 343-347.

Oliveira, J.T.; Pereira, E.; Ramalho, M.; Antunes, M.T. \& Monteiro, J.H. 1992. Carta Geológica de Portugal à escala 1/500 000. $5^{\circ}$ edição, 2 folhas. Serviço Geológico de Portugal, Lisboa.
PereIRo, T. 2015. Aproveitamento Hidroeléctrico de Ribeiradio - Ermida: Diagnóstico Arqueológico no sítio $\mathrm{n}^{\circ} 214$ - Vau: Relatório Final. Oniknos - Arqueologia Lda., $54 \mathrm{p}$.

Plisson, H. 2009. Analyse tracéologique de 4 pics d'Olga Grande: des outils pour les gravures de plein air? In: AuBry, T. (Ed.), 200 séculos da história do Vale do Côa: incursões na vida quotidiana do caçadores-artistas do Paleolítico. Lisboa, IGESPAR, I.P., Trabalhos de Arqueologia 52, pp. 436-443.

Plisson, H. 2015. Digital photography and traceology: from 2D to 3D. Journal of Archaeological Science 48:154-165.

REIS, M. 2012. Mil rochas e tal ....! Inventário dos sítios da arte rupestre do Vale do Côa. Portugalia, Nova Série 33: 5-72.

RiBEIRO, J.P.C. 1982. A indústria lítica da Gruta do Ourão (Redinha, Pombal). Notícia preliminar. Arqueologia 5: 27-31.

RIBEIRO, A. 2013. Evolução geodinâmica de Portugal; os ciclos ante-mesozóicos. In: DIAS, R., ARAÚJO, A., Terrinha, P., KullberG, J.C. (Eds.), Geologia de Portugal, Escola Editora, V. II, 15-57.

Roche, J. 1964. Le Paléolithique supérieur portugais. Bilan des connaissances et problèmes. Bulletin de la Société Préhistorique française 61: 11-27., J.D. 2009. Abordagem experimental aplicada ao estudo de estruturas gravettenses do sítio de Olga Grande (V.N. Foz Côa). Dissertação de Mestrado, Faculdade de Letras da Universidade do Porto, policopiado.

SÁNCheZ GoÑI M.F.; TURON, J.L.; EynaUd, F. \& GenDREAU, S. 2000. European Climatic Response to Milennial-Scale Changes in the Atmosphere-Ocean System during the last glacial Period. Quaternary Research 54, pp. 394-403.

SÁNCHEZ GoÑI, M.F; LANDAIS, A.; Fletcher, J.W.; Naughton, F.; Desprat, S. \& Duprat, J. 2008. Contrasting impacts of Dansgaard-Oeschger events over a western European latitudinal transect modulated by orbital parameters. Quaternary Science Review 27, pp. 1136-1151.

SANTOS, A.T. 2012. Reflexões sobre a arte paleolítica do Côa a propósito da superação de uma persistente dicotomia conceptual. In: M. J. SANCHES (Éd.) Atas da $1^{\text {a }}$ Mesa-Redonda: Artes Rupestres da PréHistória e da Proto-História: Paradigmas e Metodologias de Registo. Lisbonne: DGPC, Trabalhos de Arqueologia 54, pp. 39-68.

Sellami, F. 2009a. Les données de la séquence stratigraphique du site de Fariseu: processus de déposition et d'érosion des dépôts en limite de la plaine alluviale de la vallée du Côa. In: AUBRY, T. (Ed.), 200 séculos da história do Vale do Côa: incursões na vida quotidiana do caçadores-artistas do Paleolítico. Trabalhos de Arqueologia 52, pp. 103-108.

Sellami, F. 2009b. Les processus de formation, conservation et évolution des dépôts quaternaires sur les granites de Mêda-Escalhão: Olga Grande 4 et 14 de Pedras Altas. In: AUBRY, T. (Ed.), 200 séculos da história do Vale do Côa: incursões na vida quotidiana do caçadores-artistas do Paleolítico. Trabalhos de Arqueologia 52, pp. 109-112.

Teixeira, J. C.; VAldez, J. \& SANChES, M.J. 2010. O Abrigo da Foz do rio Tua - Alijó (Trás-os-Montes, Portugal). Identificação e estudo preliminar. Poster 
apresentado na $1^{\text {a }}$ Mesa-Redonda "Artes Rupestres da Pré-história e da Proto-história: Paradigmas \& Metodologias de Registo" (Vila Nova de Foz Côa, 26 a 28 de Novembro).

Valladas, H.; Mercier, N.; Froget, L.; Jorons, J.-L.; REYSS, J.-L. \& AUBRY, T. 2001. TL dating of Upper Palaeolithic sites in the Côa Valley (Portugal). Quaternary Science Reviews 20: 939943.

ZILHão, J. 1996. Le Paléolithique supérieur du Portugal, bilan quinquennal 1991-1996. In: M.ОтTE; J.K. KozlowsKi (Eds.), Le Paléolithique Supérieur Européen, Bilan quinquennal 1991-1996. U.I.S.P.P. Commission VIII (réunion de Forli, septembre 1996). Liège, ERAUL 76, pp. 369380 .

ZıLHÃo, J. 1997a. O Paleolítico Superior da Estremadura Portuguesa. Lisboa, Colibri.

ZILHÃo, J. 1997b. Arte Rupestre e Pré-História do Vale do Côa. Trabalhos de 1995-1996. Relatório Científico ao Governo da República portuguesa elaborado nos termos da resolução do Conselho de Ministros $n^{\circ}$ 4/96, de 17 de Janeiro. Lisboa, Ministério da Cultura, $453 \mathrm{p}$.
ZILHão, J. 2001. Le Paléolithique supérieur du Portugal, bilan quinquennal 1996-2001. In: NOIRET, P (Ed), Le Paléolithique Supérieur Européen, Bilan quinquennal 1996-2001. U.I.S.P.P. Commission VIII (réunion de Liège, septembre 2001). Liège, ERAUL 97, pp. 161-171.

ZILHÃO, J. 2006. Chronostratigraphy of the Middle-toUpper Palaeolithic Transition in the Iberian Peninsula, Pyrenae 37 (1): 7-84

Zilhão, J.; TrinKaus, E., eds. 2002. Portrait of the Artist as a Child. The Gravettian Human Skeleton from the Abrigo do Lagar Velho. Lisboa, IPA, Trabalhos de Arqueologia 22.

Zilhão J.; Aubry T.; FAustino De CARVAlho A.; ZaMBUJo G. \& Almeida F. 1995. O sítio arqueológico paleolítico do Salto do Boi (Cardina, Santa Comba, Vila Nova de Foz Côa). In: Actas do I Congresso de Arqueologia Peninsular, Trabalhos de Antropologia e Etnologia 35 (4), pp. 471-497.

Zilhão, J.; Davis, S.J.M.; Duarte, C.; SoARes, A.M.M \& STEIER, P. 2010. Pego do Diabo (Loures, Portugal): Dating the Emergence of Anatomical Modernity in Westernmost Eurasia. PLoS ONE 5 (1): e8880. doi:10.1371/journal.pone.0008880. 